\title{
DA RESPONSABILIDADE CIVIL DO COMERCIANTE PELO DEFEITO DO PRODUTO OU SERVIÇO À LUZ DO CÓDIGO DE DEFESA DO CONSUMIDOR
}

Tainara Andrea de Souza, Fábio Ferreira Morong, Maria Helena Pereira Mirante

Universidade do Oeste Paulista - UNOESTE, curso de Direito, Presidente Prudente, SP. E-mail Tainara_a_@hotmail.com

\begin{abstract}
RESUMO
Diante das dificuldades enfrentadas no cotidiano por consumidores, que são considerados hipossuficientes/vulneráveis nas relações consumeristas, o presente trabalho busca apresentar e compreender, à luz do Código de Defesa do Consumidor, a responsabilidade do comerciante quando os produtos ou serviços por ele comercializados ou prestados apresentam defeitos. 0 trabalho também compreende a análise geral da responsabilidade objetiva e não solidária do comerciante diante do fornecedor e seus efeitos jurídicos junto ao consumidor. $O$ método utilizado foi o dedutivo legal, aplicando-se a interpretação da legislação e doutrina. Conclui-se que a informação adequada sobre a responsabilidade do comerciante pode aclarar dúvidas e facilitar o exercício de direitos por parte do consumidor.
\end{abstract}

Palavras-chave: Responsabilidade civil, comerciante, defeito, produto, serviço, consumidor.

\section{OF THE CIVIL LIABILITY OF THE MERCHANT FOR THE DEFECT OF THE PRODUCT OR SERVICE IN THE LIGHT OF THE CONSUMER CODE OF DEFENSE}

\begin{abstract}
In the face of past difficulties in the daily lives of consumers, who are considered hypo sufficient /vulnerable in consumer relations, In the light of the Consumer Protection Code, the present work seeks to present and understand the responsibility of the merchant when the products or services that they commercialized or rendered defects. The work also includes the general analysis of the objective and non-solidarity responsibility of the trader vis-à-vis the supplier and its legal effects with the consumer. The method used was the legal deductive, applying the interpretation of the legislation and doctrine. It is concluded that adequate information on the liability of the trader can clarify doubts and facilitate the exercise of rights by the consumer.
\end{abstract}

Keywords: Civil liability, merchant, defect, product, service, consumer. 


\section{INTRODUÇÃO}

Diante das dificuldades enfrentadas no cotidiano por consumidores, que são considerados hipossuficientes/vulneráveis nas relações consumeristas, o presente trabalho busca apresentar e compreender, à luz do Código de Defesa do Consumidor, a responsabilidade do comerciante quando os produtos ou serviços por ele comercializados ou prestados apresentam defeitos.

O trabalho também compreende a análise geral da responsabilidade objetiva e não solidária do comerciante diante do fornecedor e seus efeitos jurídicos junto ao consumidor. Pretende ainda evidenciar os responsáveis pelos defeitos de produtos e de serviços encontrados pelos consumidores nas relações de consumo, e direcionar estes a um entendimento mais amplo e mais claro sobre os direitos que possuem.

Salienta a importância do Código de Defesa do Consumidor (CDC), trazida também pela Constituição Federal de 1988, em seu art. $5^{\circ}$, inciso XXXII (BRASIL, 1988), onde salienta a defesa do consumidor pelo Estado como uma garantia constitucional e define o CDC como "uma típica norma de proteção de vulneráveis", considerando-o de grande importância para os consumidores, que são considerados hipossuficientes/vulneráveis nas relações consumeristas, e que está cada vez mais presente no cotidiano social, haja vista estarem inseridos diariamente em uma relação de consumo.

O presente trabalho busca apresentar e compreender, à luz do Código de Defesa do Consumidor, a responsabilidade do comerciante quando os produtos ou serviços por ele comercializados ou prestados apresentam defeitos. Igualmente, procura compreender a análise geral da responsabilidade objetiva e não solidária do comerciante diante do fornecedor e seus efeitos jurídicos junto ao consumidor.

\section{METODOLOGIA}

Para cumprir o objetivo proposto, o presente trabalho seguirá os métodos dialéticodedutivo, com emprego de pesquisa à legislação, doutrina e jurisprudência acerca da matéria objeto do estudo.

\section{RELAÇÃO DE CONSUMO: CONSUMIDOR E FORNECEDOR}

De proêmio, é salutar analisar a definição de consumidor por meio de três correntes: maximalista (objetiva), finalista (subjetiva) e a Finalista Mitigada ou Finalista Aprofundada.

A corrente maximalista exige para a caracterização como consumidor, apenas um ato de consumo, de maneira ampla, podendo ser para necessidades pessoais ou profissionais, com ou sem lucros. Já a corrente finalista é mais restritiva para a proteção dos vulneráveis, onde o consumidor é o destinatário final, ou seja, que o produto seja para uso deste ou de sua família. (CAVALERI FILHO, 2014).

De outro lado, existe também a Teoria Finalista Mitigada ou Finalista Aprofundada, que foi criada pelo Superior Tribunal de Justiça (STJ). Trata-se de uma teoria intermediária, que não observa apenas a destinação do produto ou serviço adquirido, levando em consideração, também, o porte econômico do consumidor.

Nesse sentido, Cláudia Lima Marques (MARQUES, 2006, p. 305) entende que:

A partir de 2003, com a entrada em vigor do CC/2002, parece estar aparecendo uma terceira teoria, subdivisão da primeira - que aqui passo a denominar de "finalismo aprofundado" - na jurisprudência, em especial do STJ, demonstrando ao mesmo tempo extremo domínio da interpretação finalista e do $C D C$, mas com razoabilidade e prudência interpretando a expressão "destinatário final" do art. 2ㅇ do CDC de forma diferenciada e mista. (MARQUES, 2006, p. 305).

A partir daí, ressalta-se que a relação de consumo é caracterizada pela presença, em um dos polos, do consumidor art. $2^{\circ}$ da Lei no. 8.078/90, que institui o Código de Defesa do 
Consumidor (BRASIL, 1990); e no outro polo, um fornecedor, conceituado pelo caput do art. $3^{\circ}$ do da referida lei como qualquer empresa, pessoa jurídica, civil ou comercial, nacional ou estrangeira, que exerça quaisquer atividades de produção, montagem, criação, transformação, importação, exportação, distribuição ou comercialização de produtos ou prestações de serviços, que tenha finalmente a existência de um vínculo jurídico de direito material decorrente da celebração de contrato de fornecimento de produto (art. $3^{\circ}, \S 1^{\circ}$ lei n. 8.078/90), ou de prestação de serviços, nos termos do artigo $3^{\circ}$, $\S 2^{\circ}$ do CDC (CAVALERI FILHO, 2014).

Maria A. Zanardo Donato (1993, p. 70) conceitua a relação de consumo como "a relação que o direito do consumidor estabelece entre o consumidor e o fornecedor, conferindo ao primeiro um poder e ao segundo um vínculo correspondente, tendo como objeto um produto ou serviço".

Por sua vez, a relação de consumo pode ser considerada como o vínculo jurídico, ou o pressuposto lógico do negócio jurídico celebrado de acordo com as normas do CDC.

\section{DAS DEFINIÇÕES DE VÍCIO E DEFEITO DE PRODUTO E SERVIÇO E SUAS DIFERENÇAS RELEVANTES}

Em se tratando de definições, primeiramente cabe explanar que vícios são as características de qualidade ou quantidade que tornam os produtos ou serviços inadequados ou impróprios para o consumo que se destina, ou diminua o seu valor, ou que contenham indicações no recipiente, embalagem, rotulagem que o distinguem do produto. (NUNES, 2017). Importante salientar que a informação deve se dar nos idiomas em que o fornecedor busca oferecer os seus produtos e serviços, de maneira mais clara o possível, para fácil entendimento. Com efeito, o vício pode também ser, aparente de fácil constatação já no simples consumo do produto ou serviço, e os ocultos, que não podem ser detectados na simples utilização, ou seja só aparecem algum ou muito tempo após o uso.

Ou seja, no vício, seja do produto ou do serviço, o problema fica adstrito aos limites do bem de consumo, sem outras repercussões (prejuízos intrínsecos) (TARTUCE, NEVES, 2017).

Já o defeito vai além do vício produto ou do serviço, pois atinge diretamente o consumidor em seu patrimônio, seja moral, material, estético ou da imagem.

A doutrina assim ilustra:

Uma consumidora e um consumidor comparecem no mesmo momento a uma loja de
departamentos para adquirir um liquidificador. Após escolherem, resolvem comprar o
mesmo produto, da mesma marca e modelo; ambas as unidades saíram da fábrica na
mesma série de fabricação. Os dois vão para suas casas, cada um com seu liquidificador.
Cada um, em sua residência, resolve utilizar o produto. Ele pretende fazer um bolo. Ela,
um suco. Retiram o aparelho da caixa, passam uma água e preparam-se para acioná-lo. Ele
pressiona o botão. O motor, de forma violenta, gira e uma das pás de liquidificação se
quebra e sai voando, fura o copo e entra na barriga do consumidor. Ele tem de ser
hospitalizado e por pouco não morre. Ela, por sua vez, pressiona o botão. O motor, de
forma violenta, gira, e uma das pás de liquidificação se quebra e sai voando, fura o copo e
cai no chão, sem atingir a consumidora. No primeiro caso, ele sofreu acidente de
consumo. É defeito. No segundo, ela nada sofreu. Apenas o liquidificador deixou de
funcionar. É vício. Utilizando-se desse exemplo, teremos que, no caso do consumidor que
foi ferido, ele deverá acionar o fabricante do liquidificador para pleitear indenização pelos
danos materiais e morais sofridos. E a consumidora poderá pedir a troca do aparelho
viciado por outro idêntico, mas funcionando adequadamente a) na loja onde ela o
adquiriu; ou b) diretamente do fabricante. (NUNES, 2017, p 234).

Dessa forma vale destacar que vício e defeito não se confundem, pois, o defeito é caracterizado por ser mais gravoso, onde de alguma forma atinge diretamente os consumidores, o já vício é mais superficial, onde atinge somente o objeto, tornando-o impróprio ou inadequado para o uso que se destina. 


\section{DA RESPONSABILIDADE CIVIL NO CDC: BREVES COMENTÁRIOS}

Segundo os artigos 12 e 14 do CDC (BRASIL, 1990), irão responder pelos danos causados aos consumidores o fabricante, produtor, construtor, importador, independentemente da existência de culpa, pela reparação dos danos causados, por defeitos decorrentes na fabricação, construção, montagem, fórmulas, manipulação, apresentação ou acondicionamento, ou seja, conhecidos como fornecedores.

Deste modo, percebe-se que a regra geral sobre responsabilidade dos sujeitos acima elencados descrita no CDC é que todos respondem de forma objetiva e solidária.

Entende-se por responsabilidade objetiva, que todos responderão independentemente da existência de culpa, pelos danos causados aos consumidores por defeitos decorrentes desde sua fabricação, construção, ou mal condicionamento de seus produtos, por exemplo nos casos de que o comerciante desliga os refrigeradores durante a noite, para economia de energia e os produtos acabam estragando. (DINIZ,2005)

Já a responsabilidade solidária, ou seja, caracteriza-se porque todos os fornecedores que integram a cadeia de consumo, podem também ser demandados pelo consumidor a estarem respondendo pelos danos causados decorrente dos produtos ou serviços. (LISBOA, 2014)

Portanto, denota-se que a responsabilidade junto ao Código de defesa do consumidor é um dever jurídico imposto para reparar os danos causados aos consumidores decorrentes dos defeitos de produtos e serviços. Além disso, essa responsabilidade é objetiva e solidária, onde irão responder independente de culpa, pois assumiu o risco da atividade, podendo nesta hipótese qualquer fornecedor ser demandado para responder sobre o dano.

\section{DO COMERCIANTE E SUA RESPONSABILIDADE: CARACTERÍSTICAS GERAIS}

Ao tratar de responsabilidade inerente ao defeito, o CDC, como já visto, discriminou quais dos fornecedores poderiam ser responsabilizados neste caso, indicando somente 0 produtor, o construtor, fabricante e o importador, excluindo, desta forma, o comerciante. Nestes casos, a doutrina ensina que o comerciante tem responsabilidade mediata, somente respondendo nas hipóteses previstas no art. 13 do CDC. Ou seja, ele é igualmente responsável, quando o fabricante, o construtor, o produtor ou o importador não puderem ser identificados; o produto for fornecido sem identificação clara do seu fabricante, produtor, construtor ou importador; não conservar adequadamente os produtos perecíveis (BRASIL, 1990).

Outrossim, a exceção à solidariedade atinge o defeito, nos termos dos artigos 12 e 13 do CDC, pois os aludidos dispositivos consagram a responsabilidade imediata do fabricante ou de quem o substitua nesse papel, bem como a responsabilidade subsidiária do comerciante (TARTUCE, NEVES, 2017).

Ou seja, é certo que o sistema jurídico acolheu a tese da responsabilidade subsidiária em relação aos comerciantes no fato do produto. Destarte, nota-se que o comerciante poderá ter sua responsabilidade equiparada a dos demais fornecedores, respondendo, de forma secundária, pela reparação dos danos causados aos consumidores oriundos de defeitos existentes nos produtos, porém, apenas e tão somente nas hipóteses descritas no artigo 13 do CDC.

Entretanto, pode o fabricante provar que houve culpa exclusiva do comerciante, excluindo a sua responsabilidade, nos termos dos artigos acima referidos.

A título de ilustração, Tartuce e Neves (2017), apresentam um quadro elucidativo a respeito da presença ou não da solidariedade: 


\begin{tabular}{|c|c|}
\hline $\begin{array}{l}\text { RESPONSABILIDADE PELO VÍCIO DO } \\
\text { PRODUTO. }\end{array}$ & $\begin{array}{l}\text { HÁ SOLIDARIEDADE ENTRE FABRICANTE E } \\
\text { COMERCIANTE. }\end{array}$ \\
\hline $\begin{array}{l}\text { RESPONSABILIDADE PELO FATO DO } \\
\text { PRODUTO OU DEFEITO. }\end{array}$ & $\begin{array}{l}\text { NÃO HÁ SOLIDARIEDADE } \\
\text { FABRICANTE E COMERCIANTE. } \\
\text { PRESENTE UMA REPONSABILIDADE } \\
\text { DIRETA OU IMEDIATA DO FABRICANTE E } \\
\text { UMA SUPOSTA RESPONSABILIDADE } \\
\begin{array}{l}\text { SUBSIDIÁRIA OU } \\
\text { COMERCIANTE. }\end{array}\end{array}$ \\
\hline $\begin{array}{l}\text { RESPONSABILIDADE CIVIL PELO V } \\
\text { SERVIÇO. }\end{array}$ & $\begin{array}{l}\text { HÁ SOLIDARIEDADE ENTRE } \\
\text { ENVOLVIDOS NA PRESTAÇÃO. }\end{array}$ \\
\hline $\begin{array}{l}\text { RESPONSABILIDADE CIVIL PELO FATO DC } \\
\text { SERVIÇO }\end{array}$ & $\begin{array}{l}\text { HÁ SOLIDARIEDADE } \quad \text { ENTRE } \\
\text { ENVOLVIDOS NA PRESTAÇÃO. }\end{array}$ \\
\hline
\end{tabular}

Desta forma, verifica-se que o comerciante poderá ter sua responsabilidade equiparada a dos demais fornecedores, respondendo, em via secundária, pela reparação dos danos causados aos consumidores por defeitos existentes nos produtos, mas somente nas hipóteses elencadas no artigo 13.

\section{CONCLUSÃO}

Considerando a ausência de informações claras e adequadas inerentes à relação de consumo, e diante das dificuldades enfrentadas no cotidiano por consumidores, que são considerados hipossuficientes/vulneráveis na citada relação, o presente trabalho buscou apresentar e compreender, à luz do Código de Defesa do Consumidor, a responsabilidade do comerciante quando os produtos ou serviços por ele comercializados ou prestados apresentam defeitos.

Realizou-se uma breve análise geral da responsabilidade objetiva e não solidária do comerciante diante do fornecedor e seus efeitos jurídicos junto ao consumidor. Observou-se que a responsabilidade do comerciante é em regra objetiva e solidária, contudo, quando trata-se de defeito do produto ou serviço, que ocasionam danos ao seu destinatário final, não há solidariedade entre o comerciante e o fabricante; portanto o comerciante responde diretamente apenas quando estes são fornecidos sem a identificação clara do fabricante, ou até mesmo hipótese de mal conservação dos alimentos, causando danos direto a esses consumidores.

Conclui-se que a informação adequada sobre a responsabilidade do comerciante pode aclarar dúvidas e facilitar o exercício de direitos por parte do consumidor, que a par desses conhecimentos, poderá assegurar seus direitos de maneira mais célere, além de reduzir riscos e custos desnecessários.

\section{REFERÊNCIAS}

ALMEIDA, João Batista, Manual de direito do consumidor, 6. ed. rev. e atual. São Paulo: Saraiva, 2015.

BRASIL. Constituição. Constituição da república federativa do brasil. Brasília, DF: Senado Federal, 1988.

BRASIL. Decreto Lei 8.078/1990. Código de defesa do consumidor, Brasília: Senado Federal

CAVALIERI FILHO, Sergio, Programa de direito do consumidor, 4. ed. São Paulo: Atlas, 2014. 
DONATO, Maria Antonieta Zanardo. Proteção ao consumidor: conceito e extensão. São Paulo: Revista dos Tribunais, 1993.

DINIZ, Maria Helena. Dicionário Jurídico. 3 edição. São Paulo. Saraiva, 2005, p. 181.

LISBOA, Roberto S., Responsabilidade civil nas relações de consumo, 3. ed. São Paulo: Saraiva, 2012.

NERY JÚNIOR, N., Código de processo civil comentado, 4. ed. São Paulo: Saraiva, 2011.

NUNES, Rizzatto, Curso de direito do consumidor, 11. ed. rev. e atual. São Paulo: Saraiva, 2017.

NUNES, Rizzatto. Comentários ao código de defesa do consumidor, 8. ed. rev., atual. e ampl. São Paulo: Saraiva, 2015.

TARTUCE, F.; NEVES D. A. A., Manual de direito do consumidor, Direito Material e Processual, 6. ed. rev., atual. e ampl. São Paulo: Método, 2017. 